\title{
REFLEXIONES METODOLÓGICAS SOBRE LA ETNOGRAFÍA DE LOS TRASMIGRANTES SALVADOREÑOS INDOCUMENTADOS QUE VIAJAN EN TREN HACIA ESTADOS UNIDOS DE NORTEAMÉRICA
}

\author{
Susana Maybri Salazar \\ Universidad de El Salvador \\ maybri2000@hotmail.com
}

\begin{abstract}
RESUMEN
En este artículo se realizan reflexiones metodológicas para hacer etnografía sobre la emigración indocumentada. Se parte de la experiencia en la investigación sobre los trasmigrantes salvadoreños indocumentados comprendidos en el campo social trasnacional que conforman sus redes migratorias. Además, el artículo analiza la necesidad de repensar la etnografía tradicional para captar a los sujetos que están en continuo movimiento, enriqueciéndola con los aportes de la etnografía multilocal, la perspectiva parcial y el enfoque de género.
\end{abstract}

Palabras clave: etnografía, trasmigrantes indocumentados, redes migratorias, género. 


\title{
METHODOLOGICAL REFLECTIONS ON THE ETHNOGRAPHY OF UNDOCUMENTED SALVADOREAN TRANSMIGRANTS TRAVELING BY TRAIN TO THE UNITED STATES OF AMERICA
}

\begin{abstract}
This article makes methodological reflections on how to carry out ethnographic research on undocumented migration. The point of departure is an experience-based piece of research on undocumented transmigrants from El Salvador within the context of the social transnational field created by migration networks. This article also analyzes the need to rethink traditional ethnography in order to be able to understand the subjects who are constantly on the move. This enriches the ethnography with contributions from multi-local ethnography, the partial perspective and a gender approach.
\end{abstract}

Key words: ethnography, undocumented transmigrants, migration networks, gender. 
transmigrantes Salvadoreños indocumentados que viajan

en tren hacia Estados Unidos de Norteamérica

\section{INTRODUCCIÓN}

Este ensayo tiene como objetivo presentar aproximaciones metodológicas para realizar una etnografía de los emigrantes indocumentados, las cuales parten de la experiencia en la formulación de la tesis de investigación denominada «Redes de los trasmigrantes indocumentados salvadoreños en la Frontera México-Guatemala». Los tres ejes principales sobre los cuales gira la discusión son la comprensión de los procesos en el marco del campo social trasnacional salvadoreño como contexto de la producción cultural migratoria, la viabilidad y vigencia de la producción de conocimientos a partir de la observación participante haciendo efectivo el privilegio de la perspectiva parcial, y finalmente se refiere al aprovechamiento del enfoque de género para recuperar las relaciones de poder que median las redes migratorias.

\section{EL CAMPO SOCIAL TRASNACIONAL COMO CONTEXTO}

Las tecnologías de comunicación y los modos de producción característicos de la globalización están comprimiendo los espacios y el tiempo (Harvey, en Marcus 2001: 112); al facilitar la comunicación en tiempo real provocan movimientos migratorios de personas que se arraigan en sus lugares de destino manteniendo relaciones continuas y cercanas con sus lugares de origen. Paralelamente a la circulación de valores económicos, capitales y fuerza de trabajo, circulan los significados, objetos e identidades (Marcus 2001: 111), los cuales se movilizan por diversos medios electrónicos pero sobre todo a través de redes sociales formadas por personas que se ubican, se mueven y/o se comunican con o sin desplazamiento en diferentes espacios geográficos. Todos estos procesos trasforman sustancialmente los sitios de producción cultural tal y como tradicionalmente se conocían en la antropología. Estos procesos rompen con la idea persistente en esta disciplina sobre el determinismo territorial y/o la percepción de que la «sociedad humana es localizada por naturaleza y está ligada a la localidad» (Appadurai 1996: 120), pues la globalización ha cuestionado la idea de nación anclada a un territorio para ubicarla en diferentes espacios de los imaginarios de los que se consideren o se identifiquen como parte de ella, reconfigurando nuevas identidades colectivas. 
La migración salvadoreña se inserta en estos procesos para perfilar, en términos de Nina Glick (2003: 198-202), un campo social trasnacional el cual articula una densidad de relaciones llegando a conformar fuertes pero flexibles estructuras migratorias. Las redes migratorias pueden entenderse como los vínculos débiles y fuertes que se entrelazan entre sujetos que viven su cotidianidad en lugares geográficamente distantes pero que mantienen una práctica habitual (Portes 2003: 18).

En estos campos creados por la migración continua los sujetos pueden «vivir cambiando de lugar o vivir en varios lugares a la vez» (Pries 1999: 57), son sujetos que su vida trascurre trascendiendo fronteras y que pueden denominarse trasmigrantes (Pries 1999: 58) Para Ludger Pries las relaciones sociales de estos grupos no se limitan a un espacio físico cerrado o Estado nacional, sino que articulan varios espacios geográficos. La vida de los grupos entonces se extiende sobre y entre espacios geográfico-físicos diferentes. Los múltiples movimientos de personas alcanzan tanta densidad que las redes sociales conforman espacios sociales propios que trascienden a la sociedad de origen y sociedad de destino para ubicarse en diversos puntos de la trama de relaciones entre estos lugares. Por estas razones realizar una etnografía de los emigrantes salvadoreños supone situarlos en un campo físico y virtual que trasciende las fronteras de la nación salvadoreña y que obliga a considerar su vinculación con los lugares de origen, tránsito y llegada.

Además de conformar campos sociales trasnacionales, las redes migratorias manejan un capital social definido como «la suma de los recursos reales o virtuales que corresponden a un individuo o grupo en virtud de su pertenencia a una red duradera de relaciones más o menos institucionalizada de conocimiento y reconocimiento mutuo» (Bourdieu, citado en Durand y Massey 2003: 31). Muchos de estos recursos son en su mayoría intangibles, entre los que pueden mencionarse: el conocimiento de las rutas migratorias, los contactos en los lugares de tránsito y llegada, las estrategias de sobrevivencia, entre otras. Alejandro Portes (1998: 1-24) considera que este tipo de capital puede diferenciarse del capital económico en 
tanto que presenta las características siguientes: es inherente a las relaciones que existen entre los sujetos o vínculos, conlleva la acción de hacer recíproco el favor recibido u otro equivalente y puede utilizarse para ejercer control social entre los miembros de la red. De acuerdo con esto la producción del capital social supone necesariamente la continuidad del vínculo entre los que intercambian, aunque dada la flexibilidad de las redes algunos vínculos pueden ser más fuertes y permanentes que otros.

Tal y como lo afirma el Programa de las Naciones Unidas para el Desarrollo (2005: 6), la migración se ha convertido en la principal forma de participación de El Salvador en la globalización. En esta lógica la fuerza de trabajo dirige su flujo hacia los centros productivos en Estados Unidos. Contrario a la tendencia de abrir las fronteras para el libre tránsito de producción y capital, a los trabajadores emigrantes las fronteras les han sido cerradas con medidas políticas y físicas, obligándolos a realizar este viaje sin los documentos migratorios respectivos. En el lugar de origen, El Salvador, tampoco existen las condiciones para que los ciudadanos gocen de la estabilidad económica que les permita enfrentar las crisis derivadas de las políticas neoliberales y los diferentes eventos naturales que han empobrecido aún más a la población. Otro aspecto que incide fuertemente en esta dinámica es la influencia sociocultural de la gran cantidad de salvadoreños que viven y viajan en, y hacia Estados Unidos, que construyen la idea de la emigración como la mejor alternativa para la superación individual y familiar.

En este contexto, una cantidad considerable mas no definida de salvadoreños viaja sin la documentación migratoria necesaria para transitar por todo el territorio mexicano y para ingresar al lugar de destino. La condición de indocumentados los induce a la búsqueda de todo tipo de estrategias que permita realizar el viaje con éxito aun en detrimento de sus condiciones humanas o la pérdida de la vida. Una de estas estrategias es viajar mediante el apoyo que brindan las redes de migración y que constituyen el campo de migración trasnacional salvadoreño, las cuales se forman entre El Salvador, México y Estados Unidos. Las redes trasnacionales están constituidas por vínculos de parentesco y paisanaje y no 
cuentan con una estructura interna que determine jerarquías, liderazgos o la distribución de sus beneficios. Sin embargo, así como Levitt y Glick (2004: 64) lo han enfatizado para otras redes migratorias, los recursos de las redes salvadoreñas no son accesibles a todos sus miembros en la misma proporción, pues las redes están permeadas por diferencias de género, poder y estatus.

Comprendiendo este campo de relaciones se plantea la necesidad de seguir a los sujetos en ese ir y venir entre los diferentes lugares de tránsito en que se concretizan las redes. No estaría completa una etnografía de la migración salvadoreña si los antropólogos salvadoreños visualizamos ese campo como un mero campo virtual e ignoramos sus repercusiones en todo el proceso migratorio. Este campo migratorio existe y se concretiza no solamente cuando conocemos de las constantes violaciones a los derechos humanos que en él se desarrollan y que lo caracterizan, sino también existe en la cotidianidad de cada una de la vida de los trasmigrantes.

Dada la complejidad de todo ese campo, por cuestiones metodológicas y de recursos de tiempo y espacio mi esfuerzo de investigación se localizó en Arriaga, ciudad, ubicada en uno de los corredores migratorios de mayor afluencia para los trasmigrantes que viajan utilizando el tren como medio de trasporte hacia Estados Unidos, utilizando una ruta migratoria que atraviesa las Regiones Soconusco e Istmo-Costa ${ }^{1}$ (véase Figura 1). 
Figura 1. Ubicación de regiones Soconusco e Istmo-Costa.

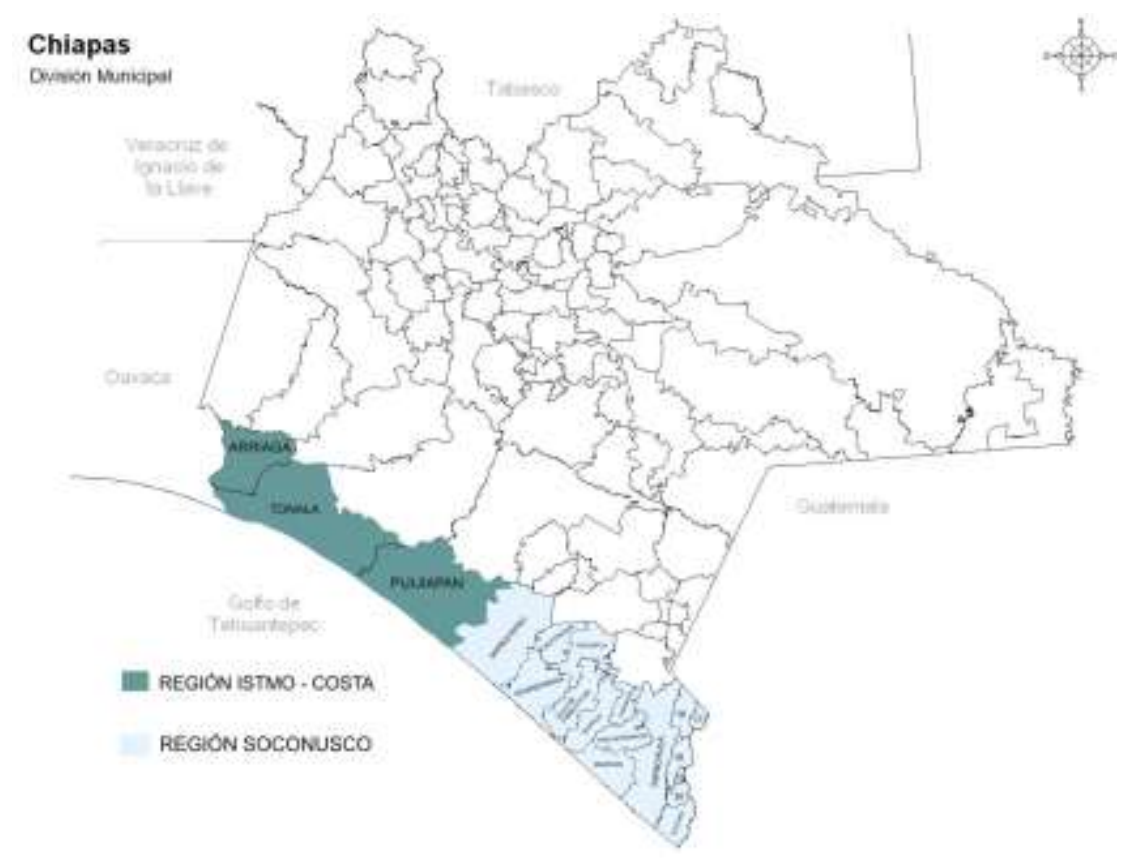

Fuente: Elaboración con base en mapas de Inafed (2005).

Arriaga también se describe como un nodo de las redes que conforman el campo social trasnacional en la medida en que cuenta con los mecanismos para que circulen y se articulen personas, símbolos y capitales de una manera dinámica e intensiva. En consecuencia la ciudad se caracteriza por proveer todos los servicios necesarios para el trasmigrante, tales como alojamiento, comunicaciones, trasferencias financieras, pero sobre todo la posibilidad de usar el tren de carga como medio de transporte. En este lugar circulan los dólares y marginalmente otras monedas centroamericanas, el tiempo también se vive entre los lugares de origen y destino. ${ }^{2}$

\section{SOBRE EL ORIGEN Y REPRESENTACIÓN DE LOS DATOS DE INVESTIGACIÓN}

En definitiva, el interés de la investigación que generó los datos para este artículo era realizar un análisis cualitativo, por ende se realizó observación participante en el periodo de 
agosto a diciembre de 2007, tiempo durante el cual permanecí en el albergue La Misericordia como voluntaria, oportunidad que me permitió relacionarme con toda clase de agentes del corredor migratorio, tales como encargados del albergue, polleros, guías, maras, empleadores, voluntarios de la parroquia, activistas de derechos humanos, investigadores, agentes migratorios, entre los reseñables.

Para captar a los sujetos en varios contextos se realizaron 51 entrevistas semiestructuradas las cuales se realizaron en el albergue, la estación de tren en Arriaga y la estación migratoria del INM, Siglo XXI. Del total de entrevistas, 44 se realizaron a los trasmigrantes salvadoreños indocumentados y 7 a otros agentes. Considerando la movilidad de los trasmigrantes, las entrevistas tenían que realizarse en una sola fase, aunque fueron complementadas mediante conversaciones informales con estas mismas personas. Las entrevistas se dirigieron a indagar sobre las historias de viaje de los trasmigrantes y sus vínculos para migrar; fueron sistematizadas en historias personalizadas y en una matriz de análisis de trayectorias para cada entrevistado. Cuando los trasmigrantes lo permitieron las comunicaciones se extendieron vía teléfono y correo electrónico, ya sea que estuvieran en su lugar de origen o llegada, pero esto fue con la minoría de los casos.

A la información cualitativa se le añadieron datos cuantitativos provenientes del registro de inscripción del Hogar de La Misericordia, los cuales se toman a cada trasmigrante al momento de ingresar al recinto. Es necesario puntualizar que los datos aquí presentados solo consideran a los trasmigrantes indocumentados salvadoreños que utilizan el albergue, ya que un grupo no determinado de trasmigrantes que viaja por la ruta Soconusco IstmoCosta no hace uso de este espacio.

Finalmente se advierte que las cifras presentadas difícilmente serán comparables con datos productos de otras investigaciones y registros de otras entidades, pues el mayor obstáculo para lograr registros confiables y representativos sobre los trasmigrantes indocumentados es el ocultamiento o encubrimiento voluntario o involuntario en el que viajan. 


\section{SOBRE LOS SUJETOS Y EL CORREDOR MIGRATORIO SOCONUSCO-ISTMO COSTA}

El viaje de los trasmigrantes salvadoreños indocumentados hacia Estados Unidos significa atravesar los territorios de Guatemala y México y sus tres correspondientes fronteras: El Salvador-Guatemala, Guatemala-México y México-Estados Unidos; en este trayecto también atraviesan fronteras nacionales, sociales, económicas, culturales y políticas a lo largo del campo trasnacional.

Los trasmigrantes salvadoreños, a los que me refiero en este ensayo, inician su viaje partiendo de su lugar de origen hacia la capital salvadoreña, en donde abordan trasportes públicos para dirigirse hacia los puntos fronterizos de Tecún Umán-Ciudad Hidalgo o El Carmen-Talismán de la frontera Guatemala-México. De ahí continúan su viaje, atravesando las regiones Soconusco e Istmo-Costa (véase Figura 1) hasta llegar a Arriaga para abordar el tren de carga que los conducirá a Ixtepec, Oaxaca, en donde trasbordan diversos trenes que los llevarán hacia la frontera de México con Estados Unidos.

El trasporte colectivo facilita el desplazamiento físico de los emigrantes por esta ruta, pero debido a que existen seis puntos de control migratorio a lo largo del trayecto (FronteraArriaga), muchos trasmigrantes optan por caminar para esquivarlos. Mientras que de Arriaga a Ixtepec realizan el viaje como polizontes del tren. ${ }^{3}$

La mayoría de estos trasmigrantes manifestó que viajar de esta manera les permite ahorrar parte de los 7,000 dólares que cuesta el acompañamiento de un coyote durante todo el recorrido. Su plan es pagar los costos del traslado desde El Salvador hasta el centro de México y luego pagar entre 1,500 a 2,500 dólares que cuesta el cruce de la frontera México-Estados Unidos con el acompañamiento de un coyote. Pero a pesar de sus insistentes manifestaciones sobre el ahorro económico que significaba esta forma de viajar también identifiqué que muchos seleccionaban esta ruta por conocerla de viajes anteriores o por el conocimiento que sobre ella les había brindado otros emigrantes. 
Cuando los trasmigrantes llegan al municipio de Arriaga se encuentran con un albergue financiado por la iglesia local denominado Hogar de la Misericordia. En este lugar, en el año 2007 se alojaron $6,439^{4}$ personas en total. Mientras que durante los cinco meses del periodo estudiado estuvieron en el albergue 2,171 trasmigrantes, que constituyó 37\% del total de albergados en dicho año.

De esta población, 35\% estaba constituida por salvadoreños, cantidad equivalente a la segunda nacionalidad con mayor afluencia al albergue. La población salvadoreña estaba compuesta mayoritariamente por $88 \%$ de hombres y $12 \%$ de mujeres. La mayoría de mujeres trasmigrantes salvadoreñas que visitan el albergue podrían caracterizarse en edades que oscilan entre los 16 y 39 años, es decir, se encuentran en edad productiva y reproductiva. El 65\% de mujeres son solteras y con hijos, el 17\% posee pareja e hijos y $14 \%$ son solteras sin hijos. Estas cifras podrían descartar la reunificación con su pareja como motivo de migración, para situarlo como motivaciones económicas de jefatura familiar femenina. Estas mujeres provenían de los departamentos de El Salvador con menor tradición migratoria (Sonsonate, Santa Ana) y de la capital (San Salvador). La tercera parte se dedicaba a actividades como empleadas domésticas y comerciantes, además de a actividades no remuneradas como ama de casa y estudiante.

El perfil del hombre trasmigrante lo describe como un hombre en la plenitud de su edad productiva (16 a 33 años); provienen de los mismos departamentos que las mujeres y al igual que ellas la mayoría (57\%) se declaró soltero; sin embargo, la cifra de hombres con pareja también es significativa (41\%). La diferencia en el estado civil soltero entre hombres y mujeres la constituye la tenencia de hijos, pues $36 \%$ de los hombres se declaró soltero sin hijos, proporción que casi duplican las mujeres con hijos. La mayoría de ellos se dedicaba a actividades productivas que no requieren un mayor nivel de entrenamiento, como jornaleros, comerciantes, obreros de construcción y empleos no calificados. También se observa un mayor número de hombres que realizan oficios técnicos, en su caso como 
carpinteros, mecánicos, panaderos, electricistas y peluqueros. En el Cuadro 1 se presentan los porcentajes del estado civil entre hombres y mujeres.

Cuadro 1. Estado civil de los trasmigrantes salvadoreños.

\begin{tabular}{|l|r|r|}
\hline Estado civil & Mujer & Hombre \\
\hline Soltero con hijos & $65 \%$ & $21 \%$ \\
\hline Casado (incluye unión libre) con hijos o sin hijos & $17 \%$ & $41 \%$ \\
\hline Soltero sin hijos & $16 \%$ & $36 \%$ \\
\hline Sin datos & $2 \%$ & $2 \%$ \\
\hline Total & $100 \%$ & $100 \%$ \\
\hline
\end{tabular}

Fuente: Elaboración propia con base en registros del Hogar de la Misericordia, agosto-diciembre de 2007.

Como ya se explicó anteriormente, este perfil incluye solo los trasmigrantes salvadoreños que se refugiaron en el Hogar de la Misericordia, dejando fuera importantes grupos que a pesar de llegar hasta Arriaga, a tomar el tren de carga, no utilizan el albergue. La diferencia entre un grupo y otro de trasmigrantes podría radicar en el capital social migratorio que manejan. Los trasmigrantes que no utilizan el albergue pueden poseer diferente poder adquisitivo y manejar otras formas y contactos de viaje, que en muchos casos podrían constituirse en capital social más empobrecido que los que poseen los trasmigrantes que sí utiliza el albergue. Tal es el caso de los trasmigrantes que aun a costa de endeudarse, ya sea por desconocimiento de la existencia del albergue o por desconfianza del mismo, pagan hoteles y hospedajes, ${ }^{5}$ o los que careciendo de recursos económicos e información sobre el albergue se quedan a dormir en las vías del tren.

Antes del huracán Stan en el año 2005, los trasmigrantes que viajaban por el corredor migratorio Socunusco Istmo-Costa abordaban el tren de carga en Tapachula con rumbo al municipio de Arriaga. Fue a partir de la destrucción de la vía férrea, a causa de dicho huracán, que los trasmigrantes se vieron obligados a transitar en trasporte colectivo y/o caminando por este tramo de $240 \mathrm{~km}$. Actualmente, al acercarse a alguna de las seis casetas 
de control migratorio, los trasmigrantes bajan y suben del trasporte colectivo con el objetivo de «rodear los retenes». Es precisamente durante esta práctica que los trasmigrantes se exponen a las mayores agresiones a sus derechos humanos, pues al rodear las casetas tienen que internarse en reductos de selvas donde atraviesan ríos caudalosos, se exponen a ataques de insectos y/o víboras y, sobre todo, a ser asaltados o violados. Cuando los recursos de estos trasmigrantes son más escasos y no alcanzan ni para pagar el trasporte colectivo, se aventuran a caminar en pequeños grupos tomando como guía la vía del tren. Entonces los peligros se vuelven constantes, se le suman la insolación, el cansancio y las llagas en los pies.

La condición de indocumentados con la que viajan estos trasmigrantes los convierte en vulnerables a constantes violaciones a sus derechos humanos y a usar formas de movilidad y sobrevivencia que atentan contra su integridad física y moral, siendo las mujeres las más expuestas. Sin embargo, aun en este ambiente hostil hacia los trasmigrantes se encontró fuerte evidencia de muestras de solidaridad y apoyo por parte de personas que habitan en la ruta y que constituyen posibilidades de formar parte de la red de migración.

Esta es a grandes rasgos la caracterización formal de los sujetos y del contexto en el que se insertan en los lugares de tránsito; vistos desde esas perspectivas numéricas y descriptivas, parecería que son un grupo más que realiza una trayectoria migratoria entre el origen y el destino. Sin embargo, al analizar sus trayectorias personales encontré un grupo que se caracteriza por hacer de la migración y de esta manera de viajar una forma de vida, con movimientos que varían en intervalos de tiempo, de manera que algunas veces parecieran estabilizados, no obstante la posibilidad migratoria está siempre latente. Así al ordenar las trayectorias de los trasmigrantes en una tipología descubrí a un grupo importante de ellos que «(migran por primera vez», en el cual se clasifican la mayoría de mujeres entrevistadas.

Otro tipo denominado «el que va y viene, pa'adelante pá atrás» son trasmigrantes capaces de regresar repetidamente sea voluntaria o forzadamente entre el lugar de origen y destino, 
y que aprovecha su experiencia guiando a nuevos trasmigrantes; grupo dominado por los hombres. El tipo de «los suspendidos en el viaje» son personas que realizan múltiples intentos sin lograr llegar a su destino y que se mueven de manera continua en el corredor, en este tipo pueden encontrarse algunas mujeres, pues muchas de ellas viajan en trasportes colectivos donde son fácilmente identificadas por agentes de migración; también se encuentran hombres que por falta de apoyos o redes son atrapados en diferentes puntos del camino, situaciones por las que realizan múltiples intentos, los hombres identificados en este tipo usualmente tienen edades mayores a 45 años, y son considerados como «gente mayor» al interior de los grupos.

Finalmente, «el deportado que regresa a los Estados Unidos»); quienes generalmente viajaron solos o con un coyote cuando realizaron su primer viaje en condiciones percibidas como menos riesgosas, por lo que intentan realizar nuevamente su viaje hacia Estados Unidos de manera individual. Pero dado el recrudecimiento del contexto de viaje generalmente solicitan a su red que les envíe un coyote para que los recoja en el lugar que se encuentren. En esta investigación de campo, no se conocieron mujeres salvadoreñas deportadas que estuvieran retornando a Estados Unidos, aunque cabe la posibilidad que muchas hayan ocultado esta condición.

\section{EL PRIVILEGIO METODOLÓGICO DE SER UNA ANTROPÓLOGA SALVADOREÑA}

Tradicionalmente, en el afán de producir conocimientos objetivos, las ciencias sociales requieren alejamiento entre el investigador y los sujetos de su investigación y niegan las particularidades humanas de los investigadores. Pero ¿qué pasa con los antropólogos que asumimos el riesgo de investigar procesos que nos atañen de manera personal y colectiva? ¿Cómo se puede ser imparcial frente a esta situación? Estas eran mis principales preocupaciones al definirme como mujer, emigrante y «con el agravante de ser salvadoreñ[a]» (Dalton 1974).

Donna Haraway (1991: 313-346) respondió a mis preguntas, su propuesta se centra en 
asumir el posicionamiento que contiene el acto cognoscitivo, aunque implique un conocimiento parcial, al fin y al cabo todos los conocimientos son parciales, la diferencia con la epistemología tradicional radica en explicitar el lugar en que se produce el conocimiento. A la luz de esta propuesta, el investigador describe su posición y sus intereses respecto a su tema de investigación, de manera que el lector y los sujetos cuentan con los elementos para analizar la forma en que dicho conocimiento fue producido y la forma de mirar del etnógrafo. Para Charles Hale, esta propuesta daría la oportunidad al investigador de adoptar posiciones que contribuyen a aumentar y enriquecer su objetividad en la medida que se define a sí mismo. «Los significados se producen mediante el diálogo entre el investigador y el investigado y se fortalece la objetividad del trabajo si uno como investigador sabe dónde está ubicado» (Hale 2007: 305).

Por otro lado, la etnografía multilocal propuesta por Marcus (2001: 111-127) es una corriente emergente que responde a los cambios de la realidad donde las tecnologías de comunicación y los modos de producción están trasformando los sitios de producción cultural, en este sentido sale de los lugares y situaciones locales de la investigación etnográfica convencional al examinar la circulación de los significados, objetos e identidades en un tiempo y espacio difuso. El objeto de estudio móvil entre diversos espacios y tiempos tiene que ser situado en múltiples localidades pues de lo contrario no puede ser entendido etnográficamente. Por lo anterior, el autor concibe que cuando se trata de migraciones la modalidad para la construcción de los objetos de estudio es la de «seguir a las personas», este procedimiento consiste en «seguir y permanecer con los movimientos de un grupo particular de sujetos iniciales»> (Marcus 2001: 118). Se trata de hacer etnografía de los mismos sujetos en diferentes localidades para captar más allá del simple movimiento de las personas de un lugar a otro. Al respecto la etnografía desarrollada en El Hogar de la Misericordia y Estación Siglo XXI permitió captar a los trasmigrantes indocumentados salvadoreños en movimiento y comprenderlos en los contextos producidos en ambas localidades. 
Ambos lugares permitían captar a los trasmigrantes en movimiento, pues, en el centro de detención o aseguramiento, como lo llaman los agentes de INM, también es un lugar en el que los trasmigrantes se preparan para iniciar nuevos intentos. En ese centro los trasmigrantes intercambian experiencias para burlar los retenes, organizan nuevos grupos para viajar, solicitan remesas de viaje o retornan a su lugar de origen.

En suma, mis esfuerzos metodológicos se centraron en apropiarme de la propuesta de seguir a los sujetos, en el marco de la etnografía multilocal (Marcus 2001: 111-127) y a la vez me permití gozar del privilegio de la perspectiva parcial (Haraway 1991: 313). Ambas proporcionan una configuración diferente a la observación participante, la cual a su vez tiene vigencia y viabilidad, como explicaré más adelante, para los estudios de los grupos que tienen a ocultarse por razones de seguridad.

A partir de un conocimiento situado en la relación sujeto-objeto planteada por Malinowski pierde vigencia porque los objetos de conocimiento se convierten en actores dialogantes (Haraway 1991: 342), y en ese camino del conocer tanto el investigador y el sujeto-objeto de conocimiento se trasforman unos a otros, pues la compresión no es tarea sólo del etnógrafo. En este ejercicio se integran diferentes perspectivas, maneras de ver, de sumar los conocimientos parciales (Haraway 1991: 342) para evitar la subjetividad y propiciar el diálogo horizontal entre sujetos de conocimiento.

Una etnografía multisituada y posicionada debería necesariamente superar la figura del «antropólogo como "muñeco de nieve", observando de modo penetrante pero invisible en su acción y helado en sus afectos y pasiones» (Hughes, en Gil: 2006: 31). En este sentido, la opción particular de los antropólogos, cuando hacen etnografía, supone exponer sus experiencias personales si con esto se contribuye a explicar y comprender a los sujetos en sus diferentes dimensiones y muestran al lector claridad sobre su punto de vista.

Bajo estos lineamientos me ofrecí como voluntaria en el Hogar de La Misericordia. El 
voluntariado implicó asumir el rol que consistió en colaborar con las actividades básicas del albergue tales como elaboración de comida, limpieza y atención de enfermos. En este lapso al encargado del albergue se le presentaron emergencias personales y me solicitaron apoyo para dirigir el albergue en colaboración con otra trasmigrante hondureña. ${ }^{6}$ En este corto periodo además de las otras actividades me encargué del mantenimiento de la disciplina, coordinación para cobro de envíos de remesas, realización y recepción de llamadas internacionales, coordinación con actores locales (unidad de salud, Grupo Beta e Iglesia), y administración de la despensa.

El rol de voluntaria me permitió vivir diferentes escenarios como ayudante y como encargada del albergue, lo cual requirió la mayor parte de mis esfuerzos para cumplir con las responsabilidades que estos cargos implicaban, llegando incluso a cuestionarme cuáles eran mis objetivos últimos al estar en Arriaga.

Los trasmigrantes, por su parte, tenían sus propias percepciones sobre mi persona y el papel que yo desempeñaba en el albergue en tanto que me identificaban como una compatriota salvadoreña. Las representaciones más frecuentes estaban orientadas a considerarme una trasmigrante, aun en el caso de que conocieran mi situación como estudiante. Esta percepción también debió haber tenido influencias sobre su comportamiento con respecto a mí, que yo percibí como una facilidad para tener acceso a conversaciones de confianza. Así también, me hizo objeto de todo tipo de proposiciones para que continuara mi supuesto viaje hacia Estados Unidos, las cuales eran realizadas por trasmigrantes, coyotes y guías, pudiendo variar desde el darme un consejo, la conquista romántica hasta la insistencia abrumadora.

Durante los pocos días que mi amiga, trasmigrante hondureña, y yo estuvimos a cargo del albergue, tuvimos que asumir una posición de autoridad al interior del mismo. Esta tarea no fue fácil considerando nuestra condición centroamericana y de mujeres, la cual nos hacía objeto de cuestionamientos por los mismos trasmigrantes quienes lo percibían como una 
manera de ocupar espacios que no nos correspondían, por ser de la misma nacionalidad «centroamericana»y por ser mujeres que necesitan ser protegidas y dirigidas. Los trasmigrantes expresaban abiertamente que cuando estaba el encargado, hombre y mexicano, todo era mejor, que nosotras no manteníamos la disciplina; nos preguntaban si no nos daba miedo estar con tantos hombres en el albergue y nos advertían sobre posibles peligros de violaciones sexuales. Por otro lado, algunos manifestaban que no podíamos obligarlos a cumplir una norma, pues éramos iguales a ellos, algunas mujeres incluso solicitaron autorización a otros colaboradores mexicanos, que llegaban ocasionalmente, para hacer uso de la cocina fuera de las horas reglamentarias, obviando nuestra autoridad. En este corto periodo, mi amiga y yo usurpamos espacios de poder, que a juicio de los trasmigrantes, correspondían al ser ciudadano mexicano y al ser hombre, como ya se comentó.

Pero en la mayor parte del tiempo que realicé mi trabajo de campo mi posición fue diferente en tanto ocupé la posición subordinada de género y nacionalidad que, según ellos, me correspondía con respecto a los demás trasmigrantes hombres y a los encargados del albergue. En este caso los trasmigrantes hombres me ofrecían su guía y protección para continuar mi viaje. En contraste, el encargado del albergue y su esposa controlaban en todo momento mis conversaciones con los trasmigrantes hombres, cuestionaban mi insistencia en recorrer la línea del tren y me prohibieron pasear en el río como lo hacían la mayoría de los trasmigrantes, todo bajo el argumento de que tenía que mantener «el respeto» de los hombres y «el respeto» como voluntaria, para lo cual me propusieron ocultar mi nacionalidad salvadoreña.

\section{SOBRE CÓMO CAPTAR LA CULTURA DE RIESGO QUE CIRCULA EN EL CAMPO TRASNACIONAL}

Las trayectorias analizadas indican el movimiento continuo y habitual que muchos de estos trasmigrantes realizan a través del corredor migratorio, y con ellos se trasmiten todo el cúmulo cultural de sobrevivencia que bien podría constituir un capital social que se trasmite 
entre emigrantes y no migrantes ubicados en cualquier punto del campo trasnacional salvadoreño.

Este devenir de los sujetos en el contexto trasnacional promueve una manera diferente de vivir en el tiempo y el espacio, ampliando de esta manera las dimensiones de lo que tradicionalmente se ha percibido como cultura. Jesús Machuca (1998: 30) realizó una revisión de las diferentes percepciones de ésta en la posmodernidad, encontrando que existe la idea de una noción ampliada de cultura, entendida como un flujo dinámico compuesto por una diversidad de elementos tangibles y simbólicos, modernos y tradicionales, que sirven como eje para la reproducción de los grupos sociales y a partir de las cuales estos grupos se diferencian de otros. Los trasmigrantes que viajan por dicha ruta migratoria y pertenecen a estas redes de migración constituyen referentes empíricos de esa conceptualización, pues en su afán por sobrevivir y movilizarse han construido y resignificado prácticas y representaciones que los diferencian de otros grupos de emigrantes y de pobladores locales para identificarse como indocumentados.

Entre estas prácticas se pueden mencionar «las remesas de viaje o del camino, ${ }^{7}$ rentear, echar la mano, mano vuelta, rodear las casetas», viajar en el tren de carga, entre otras, las que están dirigidas a la obtención de recursos económicos, recursos en especie - comida, alojamiento principalmente- y recursos intangibles como la conducción — guía-, información ${ }^{8}$ y protección. Todos esos recursos que facilitan el viaje conforman una cultura de riesgo, en el sentido que no garantizan la protección de la vida ni la dignidad humana de los viajantes y los someten a múltiples violaciones de sus derechos, variando sus afectaciones de acuerdo con sus características personales de género y edad. En este punto, no está demás recalcar que el sinnúmero de obstáculos que estos trasmigrantes deben sortear en el camino tiene su origen en una política migratoria ejercida por el Estado mexicano.

Ahora bien, comprender y compilar toda esta cultura migratoria sería un procedimiento 
sesgado si metodológicamente no se consideran las implicaciones de viajar de manera indocumentada y la manera en que las relaciones de género y edad contribuyen a darle una configuración propia a estas formas de vivir en movimiento.

La condición indocumentada de estos trasmigrantes contribuye a que los sujetos se vean así mismos como fuera de la ley, en ese sentido, sin derechos como seres humanos y sin nadie que pueda defenderlos. Es por esta razón que en las representaciones sobre sí mismos, los trasmigrantes se describían como venaditos en un campo, imaginaban el albergue rodeado de lagartos, soñaban con víboras gigantescas que los perseguían y eran asustados por pájaros horribles en La Arrocera. ${ }^{9}$ Resalta también que tenían regresiones a las zonas de combate de la época de guerra civil salvadoreña. Todas estas representaciones me fueron platicadas en las largas conversaciones que sosteníamos mientras hacíamos los oficios del Hogar de la Misericordia o esperábamos el tren en la estación de Arriaga.

Entonces, si bien las entrevistas fueron parte importante de mi recopilación de datos, estas no hubieran sido tan efectivas de no acompañarse de la convivencia con los sujetos, pues la condición indocumentado los obliga a que mantengan en el anonimato y el secreto muchas de las estrategias de movilidad y sobrevivencia, negándose a conversar al respecto con investigadores u otros agentes de ayuda humanitaria.

La observación participante fue la estrategia más apropiada para entablar relaciones con las mujeres trasmigrantes, quienes fueron las que más se negaron a ser entrevistadas formalmente, muchas porque manifestaban temor de los usos que pudiera dársele a la información y otras porque sus acompañantes masculinos les prohibían hacerlo. Sin embargo, la mayoría de estas mujeres conversaban - fuera de entrevista - con otras mujeres y conmigo sobre sus experiencias de viaje, sobre todo en el único lugar en el que no éramos observadas ni cuestionadas por los hombres: el dormitorio de las mujeres en el albergue. ${ }^{10 .}$ 
Se evidencia entonces la validez de la observación participante para trabajar con grupos que tienden a ocultarse por temor y por seguridad sea de sus otros masculinos o de los agentes que intervienen en el proceso migratorio.

\section{EL GÉNERO COMO PERSPECTIVA METODOLÓGICA EN EL ANÁLISIS MIGRATORIO}

La perspectiva de género permite comprender la diferente condición de las mujeres y hombres en una cultura dada. De ahí que para el estudio de las redes de migración, las relaciones entre los géneros constituyen una construcción social de la cual se derivan diferentes maneras de participar en ellas y de beneficiarse del capital social que se genera en sus interacciones.

Analicemos ahora por qué las condiciones de género deben ser consideradas como parte de una estrategia metodológica en el estudio de estos trasmigrantes. El viaje como tal se constituye en un proceso de adquisición de conocimientos y experiencias que permite a los trasmigrantes avanzar geográficamente de manera gradual hacia su destino y puede constituirse de múltiples intentos fallidos o exitosos. Esta experiencia de desplazamiento físico se vive de manera diferente si se es mujer u hombre, joven o adulto mayor.

Para que una etnografía de los trasmigrantes salvadoreños capte esas diferencias migratorias, es exigible la aplicación trasversal de la perspectiva de género que permita la visibilización de las mujeres en términos numéricos y presenciales, pero sobre todo que haga posible identificar las relaciones de poder (Scott 1996: 265-302) que se construyen sobre las asignaciones simbólicas de los cuerpos sexuados y las desventajas que se derivan de ellas.

Elemento fundamental es tomar como base que las relaciones de género son construcciones sociales diferentes para cada cultura, pero que en la mayoría de los casos estas suponen la subordinación de las mujeres (Lamas 1999: 162), y este es el caso de las relaciones que median entre los géneros en el campo trasnacional salvadoreño, las cuales se caracterizan 
por la asimetría y desigualdad hacia lo femenino. Entonces la metodología de análisis migratorio con enfoque de género debe facilitar el análisis de las relaciones de poder desigual.

Uno de los hallazgos principales de mi investigación es que las relaciones de género que median las experiencias migratorias del campo trasnacional salvadoreño limitan y ponen en grave desventaja a las mujeres. Hombres y mujeres salvadoreños que transitan por este camino tienen diferentes experiencias, pues las relaciones de género suponen distintos roles, identidades y espacios que deben ocupar de acuerdo con su sexo y que norman su comportamiento en relación con los otros. La manera en que de acuerdo con el género las mujeres deben de viajar y protegerse no solo limitan su capacidad de movilización y subsistencia, también hacen que inviertan más recursos económicos, situaciones que contribuyen a configurar un perfil de alto riesgo para este grupo. La vulnerabilidad de género, más la vulnerabilidad originada por la condición indocumentada y las amenazas a las que se someten en el contexto de toda la ruta migratoria, agrava los costos humanos que las mujeres tienen que asumir. Sus efectos se perciben más allá de los lugares de tránsito, pues muchas mujeres tienen que pagar el endeudamiento de su traslado, en el lugar de origen o de destino, aun y cuando el viaje no haya sido exitoso.

Para ejemplificar las aseveraciones anteriores, regresemos a la etnografía en cuestión. La Ruta Soconusco Istmo-Costa se caracteriza como de dominio masculino, no solo porque los hombres constituyen la mayoría de trasmigrantes sino también porque las mujeres se ven subordinadas a sus compañeros masculinos de viaje y demás agentes migratorios que en su mayoría también son masculinos — coyotes, delincuentes, agentes del INM, cuerpos de seguridad mexicana, encargados de los albergues, entre otros- - De ese poder masculino se desprende el miedo de las mujeres de ser victimizadas sexualmente, que se constituye en uno de los obstáculos que más afecta a las mujeres para aprovechar la cultura migratoria que se comparte entre trasmigrantes, entendido como capital social. 
Ya anteriormente se mencionaron algunas de las prácticas que caracterizan a los trasmigrantes que viajan de esta manera. Veamos con detenimiento dos de estas prácticas que algunos trasmigrantes denominaban «mano vuelta» y «hacernos bola». Como se explicó antes, se trata de un viaje gradual, y en ese sentido los trasmigrantes más experimentados se unen con los novatos y se organizan en grupos para compartir recursos tangibles e intangibles que faciliten el viaje, a esta forma le denominan «hacernos bola o bolita〉. Al interior de estos grupos los roles están divididos por género. Así los hombres se dedican a la protección y guía de las mujeres y estas debían compensar dichos servicios aportando los recursos necesarios para facilitar alojamiento, traslado y alimentación de sus acompañantes. Los gastos se pagaban con recursos que ellas traían para sufragar su viaje, remesas que enviaban sus familiares — remesas de viaje—, «rentear $\rangle,{ }^{11}$ apoyos de los pobladores o realizando trabajos ocasionales en el camino. ${ }^{12}$ Paralelo y/o complementando el «hacernos bolita» se practica «la mano vuelta». ${ }^{13}$ Esta estrategia consiste en que uno de los miembros del grupo asume todos los gastos del viaje en el primer segmento del camino, es decir, desde El Salvador hasta Arriaga, y luego otro miembro del grupo pagará otro segmento del viaje. Las personas elegidas para iniciar la mano vuelta usualmente son las que necesitan protección y guía, entre ellas las mujeres y los adultos mayores. Es de resaltar que esto significa riesgo de pérdida económica para las mujeres porque este tramo del camino es uno de los más peligrosos y con mayores posibilidades de resultar en un intento fallido.

Como es evidente los beneficios de la realización de estas prácticas también son apropiados de acuerdo con el género, pues las mujeres aunque pueden captar más recursos económicos se encuentran en una situación de desventaja que las obliga a pagar costos más altos de viaje. Muchos hombres que viajan por primera vez sufren también esta desventaja pero tienen más posibilidades de compensarla en otros intentos, pues el hecho de ser hombres los libera de los peligros de agresiones que atienden a la sexualidad y pueden aprovechar la acumulación de la experiencia adquirida en sus múltiples intentos. 
transmigrantes Salvadoreños indocumentados que viajan

en tren hacia Estados Unidos de Norteamérica

\section{CONSIDERACIONES FINALES}

En este artículo se han evidenciado la vigencia y viabilidad de la etnografía para el estudio de poblaciones migrantes indocumentadas. Sin embargo, considerando el contexto migratorio en el que se mueven los sujetos y la dinámica que los caracteriza como trasmigrantes, se evidencia que para realizar etnografía de dichos grupos es necesario comprenderlos en los contextos de origen, tránsito y destino. Dicho análisis va más allá de lo físico-geográfico ya que también se sitúa a los sujetos en el contexto del campo social trasnacional conformado por las redes migratorias.

El desarrollo del ejercicio etnográfico en el campo social trasnacional también se ve enriquecido por la observación participante realizada desde la mirada del investigador nativo, en tanto que le permite acercarse y conocer las intersubjetividades con los sujetos. Pero para superar la preocupación por la objetividad en la producción del conocimiento hacer explicito la perspectiva del que mira es una propuesta más que recomendable, exigible.

La perspectiva de género, entendida como el estudio de las relaciones entre hombres y mujeres también puede recomendarse como un eje trasversal metodológico, ya que permite conocer las situaciones de desventaja que viven ciertos vínculos o miembros de las redes migratorias, particularmente las mujeres.

Por todo lo anterior, a partir de la observación participante realizada es necesario apuntar que para levar a cabo etnografía, al igual que los trasmigrantes salvadoreños indocumentados, los antropólogos también tienen que trasgredir tres fronteras. La primera que se interpone entre el investigador y los investigados; la segunda, que existe entre la persona investigadora y su investigación, y la frontera entre la realidad y lo imaginado. Proceso que como ustedes juzgarán se caracteriza por sus altos riesgos. 
transmigrantes Salvadoreños indocumentados que viajan

en tren hacia Estados Unidos de Norteamérica

\section{FUENTES DE CONSULTA}

Appadurai, Arjun, 1996, «Sovereignty without territoriality: Notes for a postnational geography», en Patricia Yaeger (ed.), The geography of identity, Ann Arbor, University of Michigan Press, pp. 40-58.

Casillas, Rodolfo, 2007, Una vida discreta, fugaz y anónima: Los Centroamericanos transmigrantes en México, OIM CNDH, México.

Dalton, Roque, 1974, «Poema de Amor», Las historias prohibidas del pulgarcito, en http://www.literatura.us/roque/historias.html [consulta: 9 de diciembre de 2012].

Durand, Jorge y Douglas S. Massey, 2003, Clandestinos, migración México-Estados Unidos en los albores del Siglo XXI, Editorial Miguel Ángel Porrúa, México.

Gil, Carmen Gregorio, 2006, «Contribuciones feministas a problemas epistemológicos de la disciplina antropológica: representación y relaciones de poder», en Carmen Gregorio Gil, AIBR, Revista de Antropología Iberoamericana, v. 1, n. 1, Madrid, pp. 22-39.

Glick Schiller, Nina y George E. Fouron, 2003, «Los terrenos de la sangre y la nación: Los campos sociales transnacionales haitianos», en Alejandro Portes, Luis Guarnizo y Patricia Landolt, La Globalización desde abajo: Transnacionalismo, inmigrante y desarrollo. La experiencia de los Estados Unidos de América Latina, Miguel Ángel Porrúa, México, pp. 191-221.

Hale, Charles, 2007, «Reflexiones sobre la práctica de una investigación descolonizada», en Axel Köhler (coordinador), Anuario 2007. Centro de Estudios Superiores de México y Centroamérica, Gobierno del estado de Chiapas, Unicach, Tuxtla Gutiérrez, pp. 299-315.

Haraway, Donna, 1991, «Conocimientos situados: La cuestión científica en el feminismo y 
el privilegio de la perspectiva parcial», en Ciencia, cyborgs y mujeres: La Reivindicación de la naturaleza, Ediciones Cátedra y Universitat de Valencia e Instituto de la Mujer, Madrid, pp. 313-346.

Instituto Nacional para el Federalismo y el Desarrollo Municipal,2005, «Enciclopedia de los municipios de México. Estado de Chiapas», Inafed, en: http://www.elocal.gob.mx/work/templates/enciclo/chiapas/municipios/07009a.htm [consulta: 15 de febrero de 2008].

Instituto Nacional de Migración, 2006, «Estadísticas migratorias, eventos de rechazo aseguramientos y devoluciones», INM, en: http:// www.inm.gob.mx [consulta: 10 de febrero de 2008].

Kauffer, Edith, 2003, «Entre peligros y polleros la travesía de los indocumentados centroamericanos»), Ecofronteras, n. 19, Ecosur, México, pp. 9-11, en: http://www.ecosur.mx/ecofronteras/ecofrontera/ecofront19/pdf/polleros.pdf. [Consulta: 11 mayo de 2008].

Lamas, Marta, 1999, «Usos, dificultades y posibilidades de la categoría género», Papeles de Población, n. $\quad$ 21, http://redalyc.uaemex.mx/redalyc/src/inicio/ArtPdfRed.jsp?iCve=11202105 [Consulta: 9 de diciembre de 2012].

Levitt, Peggy y Nina Glick Schiller, 2004, «Perspectivas internacionales sobre migración: conceptuar la simultaneidad», Migración y Desarrollo, n. 3, México, en: http://redalyc.uaemex.mx/pdf/660/66000305.pdf [consulta: 9 de diciembre de 2012].

Machuca R, Jesús Antonio, 1998, «Percepciones de la cultura en la posmodernidad», Alteridades, $\quad$ n. $\quad 8, \quad$ UAM-Iztapalapa, México, en: 
http://redalyc.uaemex.mx/redalyc/src/inicio/ArtPdfRed.jsp?iCve=74781603 [consulta: 9 de diciembre de 2012].

Marcus, George, 2001, «Etnografía en/del sistema mundo. El surgimiento de la etnografía multilocal», Alteridades, n. 11, UAM-Iztapalapa, México, en: http://redalyc.uaemex.mx/redalyc/src/inicio/ArtPdfRed.jsp?iCve=74702209 [consulta: 9 de diciembre de 2012].

Massey, Douglas S. et al., 1991, Los ausentes. El proceso social de la migración internacional en el occidente de México, Alianza, México, pp. 396.

Menjivar, Cecilia, 2000, Fragmented ties. Salvadorean immigrant networks in America, University of California Press, Los Ángeles, California.

Programa de las Naciones Unidas para el Desarrollo, 2005, «Informe sobre desarrollo humano. El Salvador 2005: Una mirada al nuevo nosotros. El impacto de las migraciones», PNUD, s. n., San Salvador.

Portes, Alejandro, 1998, «Social capital: Its origins and applications in modern sociology», Princenton University, Annual Review of Sociology, n. 24, pp. 1-24, en: http://arjournals.annualreviews.org [consulta: 13 de febrero de 2008].

Portes, Alejandro, Patricia Landolt y Luis Guarnido, 2003, «Conclusión: Hacia un nuevo mundo. Los orígenes y los efectos de las actividades transnacionales»), en Alejandro Portes, Patricia Landolt y Luis Guarnizo, La Globalización desde abajo: Transnacionalismo inmigrante y desarrollo. La Experiencia de Estados Unidos y América Latina, Miguel Ángel Porrúa, México, pp. 377-398.

Pries, Ludger, 1999, «La migración internacional en los tiempos de la globalización. 
Varios lugares a la vez», Nueva Sociedad, v. 29, n. 164, pp 56-68.

Pries, Ludger, 2001, «The disruption of social and geographic space», International sociology, v. 16, n. 1, pp. 55-74.

Pries, Ludger, 2002, «La Migración transnacional y la perforación de los contenedores Estado-Nación», Estudios demográficos y urbanos, Colmex, México, en: http://revistas.colmex.mx/revistas/11/art_11_257_741.pdf [consulta: 6 de abril de 2008].

Ruiz, Olivia, 2003, «La migración centroamericana en la frontera sur: un perfil del riesgo en la migración indocumentada internacional»), El Colegio de La Frontera Norte, Universidad de California, Centro de Estudios Mexicanos, en: http://repositories.cdlib.org/cgi/viewcontent.cgi?article=1043\&context=usmex [consulta: 26 de febrero de 2007].

Scott, Joan W, 1996, «El género: Una categoría útil para el análisis histórico», en Lamas, Marta (comp.), El género: La construcción social de la diferencia sexual, PUEG, UNAM, México, pp. 265-302.

Valdés Montoya, Vladimiro, 2004, «El flujo centroamericano irregular con destino a los Estados Unidos: La Construcción social de la vulnerabilidad», El Bordo, Retos de Frontera, n. 14, Universidad Iberoamericana del Noroeste, Tijuana, en: http://www.tij.uia.mx/elbordo/vol14/efectos1.html [consulta: 25 de febrero de 2007].

\section{NOTAS}

\footnotetext{
${ }^{1}$ Esta Ruta denominada Soconusco-Istmo Costa fue establecida a través de sondeos de investigadores tales como Valdés Montoya 2004, Olivia Ruiz 2003, Casillas 2007, Centro de Estudios Migratorios Instituto Nacional de Migración (INM) 2006, Kauffer 2003.
} 
${ }^{2}$ Durante mi estancia fue tanta la necesidad de los trasmigrantes de saber las horas locales de ciudades de Estados Unidos y El Salvador que opté por colocar en el albergue relojes con las horas de las ciudades con mayor presencia de salvadoreños en Estados Unidos.

${ }^{3}$ Este corredor concentró en el año 2006 a $39.6 \%$ de las capturas de trasmigrantes indocumentados realizadas por el Instituto Nacional de Migración mexicano a nivel nacional (INM 2006). Según Rodolfo Casillas (2007: 43-44) entre los años 2006-2007 varios puntos geográficos de este corredor se perfilan como de muy alta violación a los derechos humanos de los trasmigrantes. Estos son Tapachula y Ciudad Hidalgo con rangos de 22 a 52 violaciones diarias, le siguen Huixtla, La Arrocera, Tonalá Arriaga y Juchitán con rangos entre 6 y 21 violaciones diarias.

${ }^{4}$ Esta cantidad registra datos de trasmigrantes que se alojaron varias veces en el albergue durante el año y periodo de estudio.

${ }^{5}$ En mis entrevistas las mujeres trasmigrantes dijeron que antes de conocer el albergue preferían los hoteles debido a que según ellas los albergues representaban inseguridad para las mujeres, al ser habitados mayoritariamente por hombres.

${ }^{6}$ Cuando me propusieron que asumiera esta responsabilidad, mi primera reacción fue negarme ya que consideraba que afectaría mi relación con los trasmigrantes pues me obligaba a asumir una posición de autoridad, pero al ser evidente la necesidad de mi apoyo, accedí. Ahora pienso que esta experiencia me dio la oportunidad de tener otra perspectiva del albergue y contribuyó a mi etnografía multilocal.

${ }^{7}$ Buena parte del dinero para los costos de traslado, hospedaje y alimentación durante el viaje es aportada por los vínculos ubicados en el lugar de destino y en menor medida ubicados en el lugar de origen. Los vínculos envían remesas de viaje que oscilan alrededor de 50 a 100 dólares. El envío se hace a través de casas de cambio ubicadas en las principales ciudades del corredor migratorio para que se vayan pagando los gastos de cada segmento.

${ }^{8}$ La información sobre la ruta a seguir y la manera de esquivar los controles migratorios, y los asaltos; dónde conseguir alimentación, y vivienda para descansar; contactos para conseguir trabajos temporales.

${ }^{9}$ La Arrocera es un sitio de paso en la ruta, conocido por la gran cantidad de asaltos y violaciones a los Derechos Humanos hacia los trasmigrantes.

${ }^{10}$ Una regla del albergue es que los hombres no pueden entrar bajo ninguna circunstancia al dormitorio de las mujeres y viceversa.

${ }^{11}$ Rentear significaba que los trasmigrantes pedían donativos a los pobladores, en las calles más transitadas de Arriaga. Se identificó aquí una resignificación del término usualmente usado entre los miembros de maras salvadoreñas para cobrar por el disfrute o uso de su territorio.

${ }^{12}$ Las dos primeras fuentes de recursos suponen en la mayoría de los casos el endeudamiento de las trasmigrantes.

${ }^{13}$ La mano vuelta originalmente es una forma que identifiqué entre campesinos hondureños para trabajar sus parcelas y tiene la misma idea de sumar los recursos para trabajar una parcela y luego continuar con la del vecino.

Fecha de recepción: 18 de junio de 2012.

Fecha de aceptación: 28 de agosto de 2012. 